Check for updates

1 Smallfield Surgery

Cite this as: BMJ 2021;375:n2827 http://dx.doi.org/10.1136/bmj.n2827 Published: 17 November 2021

\section{Designing an ecological approach to health}

\section{Gillian Orrow describes how we can cultivate personal, population, and planetary health}

\section{Gillian Orrow GP}

I have read many papers during my career, but the opening of one particular article astonished me: "Humans are ecosystems containing trillions of micro-organisms...” I read, wide-eyed. ${ }^{1}$ Back in 2018, the idea that I was interacting with ecosystems every time I treated a patient was revelatory to me. As I reflected on the importance of biodiversity to microbiome health, I was transported back to memories of time spent in the Amazon rainforest as a student. The scent of petrichor in the air, leafcutter ants creating beautiful patterns on the ground, the cacophony of monkeys and birds...The reverence and awe such memories evoked seemed a world away from the sterile clinic in which I read the paper.

As doctors, we have been trained to see and treat individuals in isolation from their environment. To prioritise industrial standards such as specialisation, efficiency, control. While we must acknowledge the huge advances such processes have enabled, we cannot escape that "human as machine" and "healthcare as factory" are implicit metaphors within industrialised healthcare. Were people machines, then a healthcare system designed to "fix" broken parts would make sense. But if we have inadvertently designed a system based on mechanistic thinking to support the health of complex, interacting ecosystems, we can begin to understand why healthcare-for all its successes-is so deeply unsustainable. After reading this paper I began musing: if people are ecosystems, should we design an ecological approach to health?

From practitioners of sustainable agriculture, I learned that an ecological approach to health can be elegantly simple. We can begin by creating conditions for health to flourish. While counter-cultural for a healthcare system that is reactive by design, this accords with a vast body of evidence. We know our lifestyles, income, education, employment, social relationships, and the built and natural environment together have far greater influence on our health outcomes than healthcare. ${ }^{23}$ Enabling active travel offers a simple example of how investment in the wider determinants of health may support health, not only at an individual level, but also for the population and the planet both now and in the future. ${ }^{4}$ At present we pour ever more resources into managing the health consequences of unhealthy environments. And yet we could equally start by cultivating common conditions for thriving and ensuring everyone can access them.

This is precisely what we are attempting in East Surrey, UK. Growing Health Together is enabling healthcare professionals within each Primary Care Network (PCN) of East Surrey Place, to collaborate as equal partners with citizens, schools, local government, the third sector, and other organisations, to improve local access to conditions for health and wellbeing. ${ }^{5}$ Just as every part of an ecosystem contributes to the health of the whole, we look to ensure that all those living or working in our area who wish to, may both benefit from and contribute to the creation of healthier places, especially those whose voices have been marginalised in the past. We wish to facilitate, in the words of the writer adrienne maree brown, "ideas that come from, and work for, more people." ${ }^{6}$ While it is still early days for our project, this approach has already resulted in a diversity of initiatives across our PCNs, reflecting the unique interests, needs, and capabilities within each place. In Smallfield, for example, self-organised health champions are running a plethora of wellbeing groups, from yoga, to singing, and art. A new active travel infrastructure is being designed to support active lifestyles while reducing local air pollution. In nearby Horley, nature-based health initiatives are being developed by and for carers, young people with disabilities, and many more. This list barely scratches the surface of the health-creating activity underway. ${ }^{7}$ Our place-based model of prevention and health creation does not intend to replace high quality clinical care. ${ }^{8}$ But rather to support the long term viability of kind and careful healthcare, accessible to all, on a healthy planet. ${ }^{9}$

On a good day, I can already see the ecosystem of mutual care supporting the health of my patients and as a practitioner, I too, feel supported. On other days the barriers that still separate so many in our society from the sources of health come into sharp focus. It is undeniable that industrialised society is destroying much of irreplaceable value to current and future health, from the biodiversity of ecosystems within and outside our bodies, to the stability of our climate. ${ }^{10-12}$ But for me, despair for such harms has been replaced by hope that, together, we may and indeed must, care for the abundance with which we are still entrusted. ${ }^{13}$ As health professionals, I believe we would do well to learn from my Indigenous hosts in the Amazon: stewards of some of the most sublime, biodiverse places on earth.

Competing interests: GO is a GP at Smallfield Surgery, co-founder and director of Growing Health Together, a board member of Active Surrey and member of Surrey Heartlands' Green Social Prescribing Committee. She has contributed to NICE Public Health Advisory Committees and worked as an NIHR Academic Clinical Fellow in general practice at the University of Cambridge, where she taught at an undergraduate level and published research on primary prevention.

Growing Health Together is on Twitter: @GH_Together

Provenance and peer review: commissioined, not peer reviewed

Moeller AH, Li Y, Mpoudi Ngole E, etal. Rapid changes in the gut microbiome during human evolution. Proc Natl Acad Sci U S A 2014;:111:16431-5. doi: 10.1073/pnas.1419136111. pmid: 25368157 


\section{OPINION}

2 World Health Organization. Regional Office for Europe. (2019).' Healthy, prosperous lives for all: the European Health Equity Status Report. World Health Organization. Regional Office for Europe. https://apps.who.int/iris/handle/10665/326879

3 Marmot M, Allen J, Boyce T, Goldblatt P, Morrison J. Health equity in England: The Marmot Review 10 years on. Institute of Health Equity, 2020.

4 Marteau TM, Chater N, Garnett EE. Changing behaviour for net zero 2050. BM/2021;375:n2293. doi: 10.1136/bmj.n2293. pmid: 34615652

5 East Surrey Place, part of Surrey Heartlands CCG https://www.surreyheartlandsccg.nhs.uk/

6 Brown AM. Emergent strategy: shaping change, changing worlds. AK Press, 2017.

7 Crisp N. Human flourishing in a health-creating society. Lancet 2021;397:1054-5. doi: 10.1016/50140-6736(21)00585-7. pmid: 33743858

8 Health Creation. The Health Creation Alliance. https://thehealthcreationalliance.org/health-creation/

9 Allwood D, Koka S, Armbruster R, et aLeadership for careful and kind careBMJ Leader 2021. doi: 10.1136/leader-2021-000451

10 Bello MGD, Knight R, Gilbert JA, Blaser MI. Preserving microbial diversity. Science2018;362:33-4. doi: 10.1126/science.aau8816. pmid: 30287652

11 IPBES. (2019). Global assessment report of the Intergovernmental Science-Policy Platform on Biodiversity and Ecosystem Services. S. Díaz, J. Settele, E. Brondízio and H. T. Ngo. Bonn, Germany, IPBES Secretariat: 1753.doi: 10.5281/zenodo.3831673https://ipbes.net/global-assessment

12 Khosla R, Jani A, Perera R. Health risks of extreme heat. BMJ2021;375:n2438. doi: 10.1136/bmj.n2438. pmid: 34620684

13 Johnson AE, Wilkinson KK, eds. All we can save: truth, courage and solutions for the climate crisis. One World, 2020. 